\title{
The Strategies and Effects of Group Counselling for University Freshmen
}

\author{
Ying Zhang ${ }^{1 *}$ \\ ${ }^{1}$ Student affairs office, Capital University of Economics and Business, Fengtai District, Beijing, 100070, China \\ *Corresponding author. Email: zyy@cueb.edu.cn
}

\begin{abstract}
At this stage, many freshmen have shown their adaption problems in the process of entering university. Aiming at the outstanding problems of freshmen in university, this paper studies the effect of group counselling on the adaptability of university freshmen. The article explains the concepts related to group counselling and then points out the typical performance of some freshmen who cannot adapt to the new environment. This paper discusses the role of group counselling in improving the adaptability of freshmen from an experimental and theoretical perspective. Finally, several suggestions were made to improve the adaptability of new students.
\end{abstract} Keywords: Group counselling, Adaptation problems, Freshmen

\section{GROUP COUNSELLING}

Group counselling is a form of psychological assistance. It uses groups and interacts with people through certain forms of activities, which triggers mutual inspiration, induction, support and encouragement among participating members, so that participating members can grow and learn in interactive experiences [1].

The two biggest characteristics of group counselling are economy and high participation. First, it can be implemented on one team at the same time. Because of this, it uses less human resources than "one-on-one" psychological counselling, which can effectively alleviate the contradiction between the current shortage of mental health teachers in universities and the sharp increase in the number of students [2]. At the same time, team activities combined with open, funny and lively tutoring methods are more attractive to university students, which makes it highly participatory, interactive, and effective. In the specific coaching process, participants completed different tasks through four processes: warm-up, cohesion, exploration and conclusion under the conditions of resource sharing, real scene and group interaction [3].

\section{ADAPTATION PROBLEMS}

\subsection{Living Adaptation}

The environment that freshmen need to adapt to includes the off-campus environment and the on-campus environment. First, most freshmen need to face the impact of regional and cultural differences. They need to face major changes in language accents, dietary tastes, and accommodation environments. Some students stay away from their hometown and experience the new regional culture, which is more obvious for students who cross the border between
North and South [4]. Second, some students who lack the ability to live independently and live on campus are more uncomfortable. After officially starting university life, some freshmen have developed unhealthy habits such as laziness, improper diet, irregular schedules and Internet addiction in an unsupervised environment.

\subsection{Study Adaptation}

University freshmen will have various psychological problems related to learning in the process of changing from "managed" to "self-managed"[5]. In high school, most teachers use the paddling teaching method, but at the university, students rely on self-study. At this time, students will be more confused. Freshmen are often less selfdisciplined and unable to control their behaviour. It not only requires students to improve their self-learning abilities, but also establishes relationships with new teachers and students.

\subsection{Interpersonal problems}

Compared to high school life, university life is more colourful. Students come from all over the country, and there are many differences in living habits and language. Unlike the relatively simple interpersonal relationship of "learning only" in middle school, they don't know how to get along with classmates from different social backgrounds [6]. The interpersonal relationship is complicated.

\subsection{Self-perception problems}

After entering the university, freshmen will be confused about setting goals. Freshmen have just entered university, and they don't understand their majors and have too many ideas for the future, which makes them even more confused. 
At the same time, university competition is far more intense than high school. It takes more efforts to stand out in the university because it is not only the competition of scores, but also the comprehensive quality of a person.

\section{EXPERIMENTAL EFFECT}

\subsection{Design of group counselling}

This article uses an university in Beijing as an example. On the basis of grasping the characteristics of students, classbased units are used to develop adaptive group counselling for freshmen among all students. The content of the counselling is divided into four units ("self-exploration", "dream and growth", "positive psychological quality" and "interpersonal relationships"). Through different activities, students are guided to find their own positions, harmonize interpersonal relationships and enhance communication skills.

\subsection{Scale analysis of group counselling}

\subsubsection{Objects}

Before the counselling, 600 students were randomly selected from the 2,500 first-year students at the university. The effective participants were 591, including 239 males and 352 females.

\subsubsection{Measurement}

At the beginning and end of group counselling, group measurements of the Chinese University Student Adaptation Scale (CCSAS) [7] were conducted for participating students. Questionnaire surveys and return visits were conducted after the group ended. CCSAS includes 7 factors: interpersonal relationship adaptation, learning adaptation, campus life adaptation, job selection adaptation, emotional adaptation, self-adaptation, and satisfaction. The scale consists of 56 questions, using a 5point scale, and scores 1-5 based on "very not consistent", "not very consistent", "unsure", "somewhat consistent" and "very consistent".

\subsubsection{Methods}

Use SAS 9.1.3 software. T test and Pearson correlation coefficient analysis.

\subsubsection{Analysis}

As can be seen from the results in Table 1, before and after group counselling, the students tested had significant differences in seven aspects. The aspects of campus life adaptation, self-adaptation, and emotional adaptation are particularly obvious. This shows that the group counselling can effectively resolve the psychological problems caused by the freshmen's adaptation problems, help the freshmen to develop and mature better.

Table 1 experimental results

\begin{tabular}{c|c|c|c}
\hline Factor & Before the test & After the test & $\mathbf{t}$ \\
\hline $\begin{array}{c}\text { interpersonal relationship } \\
\text { adaptation }\end{array}$ & $3.87 \pm 0.83$ & $4.03 \pm 0.18$ & $-2.040 *$ \\
learning adaptation & $3.98 \pm 0.75$ & $4.11 \pm 0.15$ & -2.054 \\
campus life adaptation & $4.56 \pm 0.60$ & $4.78 \pm 0.16$ & $-2.436 *$ \\
job selection adaptation & $3.54 \pm 0.61$ & $3.89 \pm 0.31$ & -2.865 \\
emotional adaptation & $4.02 \pm 0.72$ & $4.41 \pm 0.29$ & $-2.219 *$ \\
self-adaptation & $4.08 \pm 0.65$ & $4.52 \pm 0.27$ & -1.145 \\
satisfaction & $3.92 \pm 0.91$ & $4.26 \pm 0.61$ & $-1.297 *$
\end{tabular}

\subsection{Survey feedback on group coaching}

It can be seen from the questionnaire survey that most students have improved in group counselling. $68.02 \%$ of students apply the knowledge learned in group counselling to real life. $84.77 \%$ of students have a more comprehensive understanding of themselves. $65.8 \%$ of students have achieved significant results in real life. $95.9 \%$ of students hope to continue to participate in group counselling in the future. The students stated in the message that group counselling helped them to improve their self-understanding, guided them to learn to listen, praise, appreciate and accept others, improved their social skills and ability to adapt, communicate and cooperate.

\section{The Effect of Group Counselling}

\subsection{Correct understanding}

Group counselling makes it very common for freshmen to realize that there is discomfort in the environment, interpersonal, study or self-awareness. At the same time, the problems of different students are similar. Group counselling can resonate with students, help them find solutions to other students who have encountered similar problems.

\subsection{Correct communication}

Group counselling focuses more on freshmen than traditional admissions education. It helps freshmen to reach consensus through mutual communication and establish 
good interpersonal relationships. At the same time, it can also cultivate the ability of freshmen to share and empathize, which make students effectively solve problems in life and study.

\subsection{Comprehensive and objective self- perception}

On personal development, group counselling helps students set goals and build plans. It helps them to more accurately determine their situation and have a more objective evaluation of themselves. It effectively helps them learn to take the university as a new stage, and encourage students to identify new development goals and develop actionable plans for achieving them.

\subsection{Good relationship}

Group counselling is conducted under the guidance of a school teacher specializing in mental health education. They can grasp the situation of the whole class through the specific performance of the students, and further understand the personality characteristics of the students. At the same time, it easier for them to establish good relationships with students.

\section{SUGGESTIONS}

First of all, we should analyse and study the characteristics of students' psychology and thoughts. After finding common problems that students face, we should start group counselling activities in time.

Second, we must pay attention to the cultivation of the student who leads in daily work. It is a kind of living force that can make it better develop group counselling.

Third, enriching students' campus life can enhance the role of group counselling. Campus cultural activities, combined with group counselling, can improve the quality of students and help students build self-confidence.

\section{CONCLUSION}

Through empirical analysis and questionnaire survey, it can be clearly found that group counselling can effectively help freshmen to solve psychological problems caused by adaptive problems, help freshmen to realize self-cognition and interpersonal communication.

In practice, we can solve the problem of freshmen's adaptability by timely carrying out group counselling, cultivating student leaders and carrying out student activities.

\section{REFERENCES}

[1] yao enju. Research on the intervention of anti-business group counselling on entrepreneurship emotion and entrepreneurship ability of college students [J]. Quality education in western China. 2020 (01)

[2] Ou cailing. Application of group counselling technology in college students' academic counselling [J]. Western quality-oriented education. 2019 (03)

[3] YinNing. Applied research of group counselling in mental health education curriculum [J]. Think tank times. 2019 (37)

[4] ZhengRong. Research on the influence of group counselling on mental health and adaptability of freshmen in higher vocational colleges [D]. Qinghai normal university, 2012

[5] Lu zhaoxia, Li haixing, Hou caixia, Ren hualiang. Study on the impact of group tutoring on freshmen's adaptability [J]. Journal of Taiyuan university of technology (social science edition). 2013 (02)

[6] GuoHui, SuMeng, ChenXu, Li yandi. Experimental study on adaptive group counseling for freshmen $[\mathrm{J}]$. Chinese medicine education. 2012 (02)

[7] Wang Rui, Wu shaoyi, Liu yan-xun. Test analysis of Chinese college students' personality scale and psychological adaptation scale on 6913 freshmen [J]. Journal of Shandong university (medical edition), 2009,47 (11): $132-134+137$. 